Krebs, by the use of a more powerful and a lighter motor and a long balloon, reached a speed of about 5.5 metres a second in their first two experiments, and 6.5 metres a second in their recent experiments of Nov. 8, 1884, or 23.5 kilometres an hour, with a five-horse power, and fifty revolutions of the screw a minute.

On the 9 th of November, says Tissandier, the wind was moving at the rate of 8 kilometres an hour. When the balloon was going with the wind, its speed was equal to 23.5 plus 8 kilometres, or 31 kilometres, an hour: on the other hand, when it went against the wind, its speed was 23.5 kilometres minus 8 kilometres, or 15.5 kilometres, an hour. The balloon was easily guided in all directions.
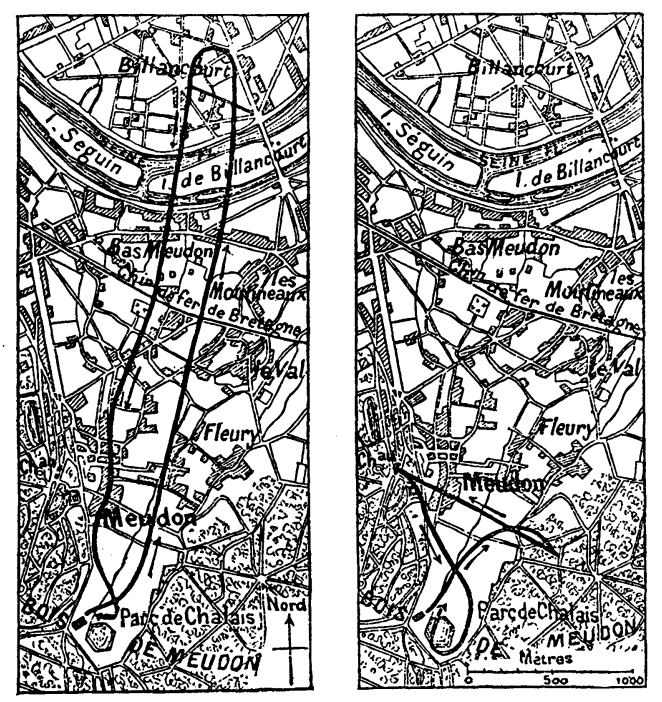

The first ascent took place at noon. When the balloon had risen above the surrounding obstructions, the working of the screw was begun; and the balloon, tacking about, was directed in a straight line toward the viaduct of Meudon, which it soon reached. It crossed the Seine below the bridge of Billancourt, became entangled on the right bank of the river, and the motor was stopped, and the balloon allowed to go with the wind, in order to measure the rate of the current. After a rest of five minutes, the machine was again put in motion; and the balloon, guided by the rudder, described a semicircle of about 160 metres diameter, and returned to its starting-point at a slow rate, but with perfect stability. At three P.M. Renard and Krebs began a second experiment. The balloon arose a second time, and made several excursions in the neighborhood of Chalais; but the fog was so thick, that the second ascent only occupied thirtythree minutes through fear of losing sight of the landing-place. A return to the place of departure

have not been able to provide a shelter for the inflated balloon, that it might be ready to set out in favorable weather. was easily effected, as before. The accompanying maps give the exact routes of the two trips.

These new experiments are decisive. Navigation of the air by means of long balloons provided with screws is demonstrated. We will repeat, what we have already said many times, that to be practicable and useful, aerial ships must be made very long, of very large dimensions, which shall carry very large machines, capable of giving a speed of from 12 to 15 metres a second, allowing their working at almost any time. When the wind is high, or there is a squall or tempest, aerial ships must remain in port, as other vessels do. It becomes now only a question of capital.

\section{A NEW LAW OF ORGANIC EVOLUTION.}

I HAVE in another place given many reasons for believing that the male cell has, by division of labor, gradually acquired the function of exciting variation, while the ovum transmits the established characteristics of the race. The following facts, among others, seem to indicate that a specialization of this sort actually exists. $10^{\circ}$ There is no evidence that the functions of the two sexual elements are alike, but the possibility of parthenogenesis shows that the ovum in itself can transmit all the established characteristics of the race. $2^{\circ}$. Organisms born from fertilized eggs or seeds are much more variable than those which are produced asexually. $3^{\circ}$. The children born from a male hybrid with the female of either pure form are much more variable than those from a female hybrid with the male of either pure form. $4^{\circ}$. Parts which are confined to males, or which are of more functional importance in males than in females, are much more variable than parts which are confined to females, or which are of more functional importance in females than in males. $5^{\circ}$. Males are more variable than females. $6^{\circ}$. The male leads, and the female follows, in the evolution of new features, as is shown by the fact that the females of allied species are more like each other, and more like the young, than the males are. This cannot be due to sexual selection; for it holds true to a remarkable degree in domesticated pigeons, and in other animals which are paired by the breeder.

Now, if it is true that the tendency to vary comes through the influence of the male parent, it will be for the advantage of the species to give birth to an excess of females, so long as the conditions of life are favorable, and change is not needed, and to give birth to an excess of males whenever the conditions of life become unfavorable, and thus demand new modifications.

Düsing has recently published ${ }^{1}$ a very valuable and highly suggestive series of papers upon the laws which regulate the sex of the embryo in mankind, and in other animals, and in plants; and the facts which he has brought together seem to show that this specialization actually exists, and that a favorable environment

\footnotetext{
1 Jenaische zeitschrift, xvi. iii. 1883, 428, and xvii. 1884, 592940 .
} 
causes an excess of female births, while an unfavorable environment causes an excess of male births.

Among mankind the conditions of life are so much under control, that it is difficult to say just what constitutes a favorable enviromment; but I think we may safely conclude that a high birth-rate indicates that the conditions of life are favorable, and that a decrease in the birth-rate indicates decreased prosperity, and that human races which are disappearing are so doing because surrounding conditions are no longer favorable.

Düsing gives many facts to show, that, as the birthrate increases, the number of boy-births to each 100 girl-births decreases, and vice versa. At the Cape of Good Hope the Boers are very prolific: six or seven is a small family, and from twelve to twenty children are not unusual, and 100 girls are born to every 97.2 boys. The Hottentots, on the other hand, are very infertile: many of the women are barren, and they seldom have more than three children, and 103.9 boys are born to each 100 girls.

The birth-rate is higher in towns than it is in the country, and the ratio of boys is greater in the country than it is in the towns. In 1881 the average for the whole of Prussia was 106.36 boys to each 100 girls; and in all the towns the boy-births were below this average, and above the average in the country. Ploss has shown that in Saxony the ratio of boy-births rises and falls with the price of food.

From nearly 10,000,000 births, Düsing has compiled a table to show the birth-rate, and the ratio between the sexes, for each month in the year; and this table shows that the ratio of boy-births is the highest when the birth-rate is lowest. In March the birthrate was highest $(942,488)$, and the ratio of boy-births was lowest (105.92 boys to each 100 girls); while in June the birth-rate was lowest $(812,469)$, and the ratio of boys highest (106.77).

Among the lower animals, it is difficult to obtain statistics: but Düsing states that domesticated animals are more prolific than their wild allies, and that there is a greater number of female births; that, when animals are taken from a warm to a cold climate, the ratio of male births increases; and that leather-dealers state that they obtain most female skins from fertile regions with rich pastures, and most male skins from more barren countries.

The power of parthenogenetic reproduction seems, in many cases, to have been acquired in order to permit an unusually great and rapid increase in the birth-rate, when the conditions of life are unusually favorable; and in these cases the parthenogenetic eggs give birth to females almost exclusively. Among the parthenogenetic Cladocera, both males and females are found in the fall and in the early spring; but during the warm months only females are found, and they multiply so rapidly, that, according to Ramdohr, a female Daphnia can in sixty days produce 1,291,370,075 parthenogenetic female descendants. As the supply of food fails in the fall, males make their appearance; and Kurz has shown that any unfavorable change causes the production of males. He says that males appear when food fails, when the water dries up, when it becomes too dense, when it acquires an unfavorable temperature, or, in general, when there is a decrease in prosperity. From these and many other facts recorded by Düsing, I think we may safely conclude, that among animals and plants, as well as in mankind, an unfavorable environment causes an excess of male births, and a favorable environment an excess of female births.

Now, why should this be so? If the welfare of the species can be secured, under a favorable environment, by females alone, why are males needed when the environment becomes unfavorable? I believe that we have, in the facts recorded by Düsing, an illustration of one of the most important and far-reaching of all the adaptations of nature, - an adjustment which tends to cause variation when it is needed, and to keep things as they are, so long as no change is demanded. As the conditions of life become unfavorable, variation becomes desirable in order to restore the adjustment between the organism and its environment; and this is secured by an increase in the ratio of male births.

That this is thestrue explanation of the phenomena, is shown, I think, by the contrast between domesticated animals and captive animals. The fact that an animal has become domestic shows that it finds in captivity a favorable environment; and Düsing says that domestic animals are exceptionally fertile, and that they produce an excess of females. Animals which are kept as captives in menageries and gardens, have, as a rule, no fitness for domestication; and Geoffroy St. Hilaire says that individuals born in menageries are usually male, while skins sent to museums are usually female; and that the attempt to domesticate a wild animal increases the number of male births. Düsing states that captive birds of prey, and carnivorous mammals, are very infertile, and that the young are nearly always males.

The wild human races of Oceanica and America are much like captive animals, as they have been suddenly thrown into contact with a civilization which has been in Europe the slow growth of thousands of years. Food and climate have not changed, but a new element has been introduced into their environment. The New-Zealanders are very infertile, and nearly all the children are boys; and the census of 1872 for the Hawaiian Islands gave a ratio of 125 male births to each 100 female births.

I believe we may see, in these instances, the last struggle of nature to save the race from extermination by the production of a favorable variation. It is proper, however, to point out that Düsing himself gives a different explanation of the excess of male births under unfavorable conditions of life, although I believe that examination will show that his explanation is inadequate.

He says that the excess of male births is for the purpose of preventing close inter-breeding. He shows that inter-breeding causes sterility, small size, and lack of general vigor and vitality; and he also shows that these effects are most marked when the other conditions of life are least favorable, and that no evil effects follow inter-breeding when food is abundant, 
and when the environment in general is conducive to prosperity. Since the evil effects of inter-breeding become more marked as the environment becomes less favorable, and as male births. are then in excess, he believes that the excessive production of males is an adaptation which has gradually been acquired by natural selection, for the purpose of preventing close inter-breeding at the time when it is injurious; but, as an injurious property cannot be established by natural selection, the evil effects of inter-breeding cannot be primary. The end which is advantageous, and which has been secured by natural selection, is the crossing or sexual union of individuals which are not closely related. As the object of crossing is to secure variability, it is most necessary when change is needed; that is, when the conditions of life are unfavorable.

Natural selection has accordingly acted to secure this by rendering the offspring of a cross more able to resist an unfavorable change than the offspring of closely related parents, or the parthenogenetic children of a single parent; and the excessive production of males under an unfavorable environment is for the purpose of securing variation, rather than the prevention of inter-breeding.

This very suggestive topic opens many fields for research where our information is very scanty; and any readers of Science who are able to contribute information regarding the number of births of each sex in wild or captive or domestic animals will help to a clearer insight into an extremely interesting and important problem. The writer will gladly receive and tabulate information upon this point, and will give proper credit to contributors.

Johns Hopkins university, Baltimore.

W. K. Brooks.

\section{CONTEMPORARY SOCIALISM.}

Contemporary socialism. By JoHN RAE, M.A. New York, Scribner, $1884.13+455$ p. $8^{\circ}$.

Among the merits of this volume may be mentioned the spirit with which the subject of socialism is approached. The author, understanding that his position is not that of an advocate either of existing society or of any proposed future social form, attempts to present an impartial but critical account of the schemes which contemporary socialists assure us will inaugurate an earthly paradise. Mr. Rae indulges neither in abuse nor declamation nor frightened outcry, but manifests a judicial calmness of temperament, befitting a man of science.

The scope of this work is indicated by the titles of the chapters, which are the following : Introductory, containing a preliminary survey of the field; Ferdinand Lassalle; Karl Marx; The federalism of Carl Marlo; The socialists of the chair ; 'The Christian socialists ; Russian nihilism; Socialism and the social question; Progress and poverty ; Henry George.

The arrangement of topics is not at all what one might expect, and is due, perhaps, to the fact that the book consists, in part, of articles previously published in the Contemporary review and the British quarterly. These have been enlarged, and supplemented with additional chapters, and the old and new are not well joined together. It exhibits more or less of the character of patchwork in many places; each chapter not leading naturally to the following, nor being an outgrowth of what has preceded. Thus Lassalle, who built on Marx and Rodbertus, and who simply interpreted their doctrines to the common people, kindling in their breasts a fire of enthusiasm not yet extinguished, is treated in the second chapter ; while Karl Marx, his logical predecessor, follows. Rodbertus, the father of scientific socialism in Germany, of whom Marx is only a further evolution, receives no separate treatment at all, and is barely alluded to in the chapter on Marlo. The greatest figure in modern socialism is thus passed by in scarcely half a dozen words, in a work professing to give a picture of contemporary socialism. French socialism fares scarcely better, receiving only three or four pages in the introductory chapter, and that in a work of four hundred and fifty-five pages. This is certainly inadequate. Henry George, on the other hand, who, it is acknowledged, is not a socialist in the ordinary acceptation of the term, receives seventy-seven pages.

'The book is a disappointment; because it is a series of detached essays, instead of a connected whole, and is not what a perusal of the author's articles in the Contemporary review might reasonably have led one to expect. 'The entire work betrays either indolence, or lack of sufficient time for the adequate performance of the author's task; for it ought to have been re-written, the style improved, a more philosophical and symmetrical arrangement secured, and more careful attention given to the most recent phases of contemporary socialism. Parts of the book were written several year's ago, and, though perhaps true then, are not accurate now; and, even in the apparently more recent additions, there is an oversight of what is transpiring at the present time. Thus, on p. 56, Mr. Rae uses these words: "England is the only great country where socialism has at present neither organ nor organization that reaches the public eye or ear." 'This sounds strange, for in this country we hear frequently 